\title{
In-situ Strain Measurement of Submerged Arc Welding Process Through Application of Electronic Speckle Pattern Interferometry
}

\author{
Uwe Reisgen*, and Rahul Sharma*, \\ *RWTH Aachen University, Welding and Joining Institute, Aachen, 52062, Germany \\ †Corresponding author : sharma@isf.rwth-aachen.de \\ (Received July 11, 2017 ; Revised July 13, 2017 ; Accepted July 21, 2017)
}

\begin{abstract}
In this work the submerged arc welding process with cold wire addition (SAW-CW) has been analysed regarding the strain buildup during welding. Bead-on-plate welds were made onto sample plates made of Nickel based Alloy 617 with varying cold wire addition. A 3D electronic speckle pattern interferometry (ESPI) device was mounted under the sample to measure the surface strain field. Subsequently the residual stress field in cold state was determined using the ESPI hole drilling method.

The results showed that the strong impact of cold wire addition on the weld pool geometry leads to a changed strain field during welding and cooling. When considering strain measurements made with neutron diffraction, the ESPI method gives additional surface related strain information with higher spatial resolution.
\end{abstract}

Key Words : In-situ strain measurement, Alloy 617, ESPI, Submerged arc welding, Cold wire

\section{Introduction}

The application of arc welding processes on metallic materials implies high gradients of temperature, strain and stress due to the high power density of the moving heat source. Besides the deterioration of mechanical properties, the buildup of residual stresses follows up thermal manufacturing processes.

The numerical description of fusion welding processes with moveable heat source depends on accurate equivalent heat source models, which deliver heat into the weld zone. The complex behavior of heat source and liquid phase then leads to the formation of the fusion zone. After solidification of the weld metal, thermomechanical material models make the strain distributions of the weld zone accessible for further investigation. In order to validate such models through experimental investigations, it is inevitable to determine the transient temperature and strain distribution in the vicinity of the weld pool.

A central issue in welding of high alloyed steels and nickel based alloys is the formation of hot cracks. These welding defects occur if a critical combination of chemical composition, mechanical load and welding parame- ters are used. Therefore it is difficult in high performance welding processes to hit the suitable parameter window. The submerged arc welding process (SAW) is such a high performance welding process and it is often applied for manufacturing of thick walled components because of its high deposition rate, deep penetration and process stability. In some nickel base alloys it is even difficult to set up even a SAW process with sufficiently low heat input to prevent hot crack formation. Furthermore the loss of alloying elements through burn-off to the slag limits the feasibility of SAW for creep resistant nickel based alloys.

To overcome these restrictions the submerged arc welding with cold wire addition (SAW-CW) process has been investigated in the past ${ }^{1,2)}$. Slight evidence for lower hot crack formation when using SAW-CW led to the conduction of an in-situ-diffraction experiment to compare the process induced elastic strains in the hot surrounding zone of the weld pool ${ }^{3)}$. It was found that the high temperature strain differed significantly between both process variants. Due to the relatively large gauge volume of the neutron diffraction method and the complexity of the in-situ experiment, the spatial resolution was low with regard to the weld pool dimensions. This lead to the development of an alternative in-situ strain 
measurement setup using an optical method, which is presented here.

\section{Submerged Arc welding with cold wire addition}

The common SAW process is carried out using a continuously fed wire electrode. By applying the welding voltage between the contact piece and the base metal, an electric arc burns under the welding flux which is melted to form the slag pool. Metal vapour and gasified slag components form the cavity wherein the electric arc burns and the metal droplet transfer takes place.

The SAW-CW process complements an additional welding wire, which is fed into the weld pool leading or trailing the welding electrode. Since there is no voltage applied between additional wire and base metal, the melting is exclusively induced by the excessive heat of the weld pool. Since the weld pool in front of the electrode is very narrow, only a trailing cold wire could prevent hitting the cavity, except for low welding speeds. In this trailing arrangement the loss of alloying elements is reduced as the droplet does not pass the arc zone. The electrical process characteristics are not influenced by the cold wire feeding, so that no change in heat input occurs, compared to the single wire SAW. Since the weld bead geometry is heavily influenced with increasing cold wire feed rate, it is difficult to formulate general qualities of the SAW-CW properties. For high alloyed steels it was reported that the cooling times could even increase when cold wire was fed into the weld pool without changing the electrical process parameters nor the heat input per unit length ${ }^{4)}$. For nickel based alloys some indications exist that the hot crack formation could be reduced when SAW-CW is applied ${ }^{2)}$.

\section{Strain measurement during welding}

For the measurement of strain in welded samples a wide range of measurement techniques can be used. However this only applies for ex-situ measurement at room temperature. The formation of residual stresses is influenced by the strain distribution at high temperatures as well as is the hot crack formation. To carry out time and spatially resolved strain measurements during welding, mostly optical and diffraction methods are feasible, since no direct contact between the hot sample and a measurement device is needed. One such optical strain measurement method is the Electronic Speckle Pattern Interferometry (ESPI). This technique makes use of the interference pattern, which can be observed when a surface is illuminated by two coherent light beams with a phase shift of $\lambda / 2(\lambda=$ wavelength) (Fig. $1)$. Since the light is scattered on the structure of the

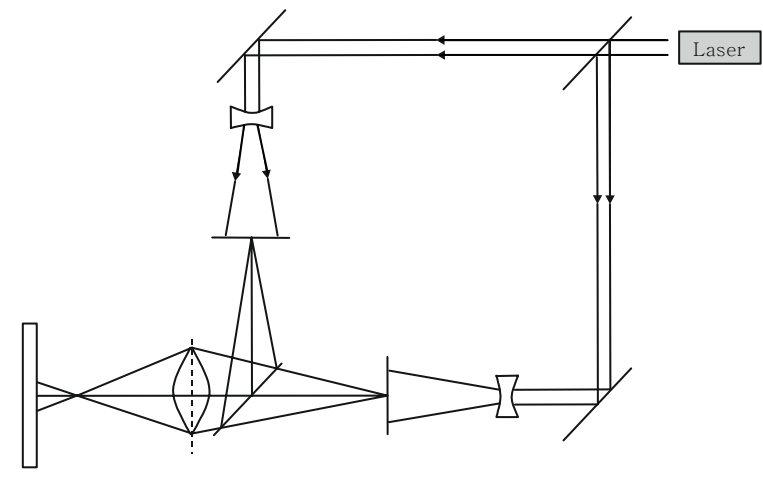

Fig. 1 Optical path to generate speckle patterns for displacement measurement ${ }^{6)}$

surface, a characteristic speckle pattern can be observed, which reacts very sensitive to any surface deformation. By overlaying the deformed pattern with an initial reference pattern, a fringe pattern is formed, which enables to calculate the surface displacement ${ }^{6}$. The method is applicable for three-dimensional surface displacement measurement in the sub-micron range, but is very susceptible to any displacement between measurement device and measurement object.

\section{Experimental approach}

In order to measure the strain distribution induced by SAW-CW, bead-on-plate welds were carried out. Since the flux covers the welding zone, the backside of the specimen plates was observed through a hole in the sample holder during welding with a commercial ESPI strain measurement system (GOM ESPI). A comparable setup was also used in ${ }^{7)}$ for the TIG welding process The sample plate was clamped so that only in-plane displacement was possible to prevent difficulties during ESPI measurement (Fig. 2).

In preliminary experiments, the distortion of the welded plate exceeded the focus depth of the used lens, so that no measurement was possible immediately after welding. This lead to the development of a special clamping table.

The distance between measuring device and sample plate was set to $300 \mathrm{~mm}$ in order to achieve stable

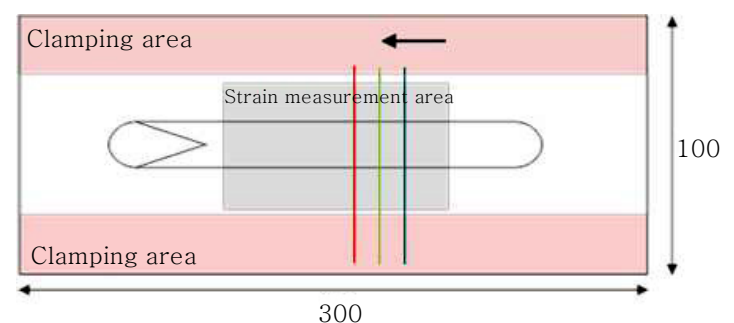

Fig. 2 Position of measuring area and clamps on the sample surface 
measurements, after consideraton of a beneficial compromise between acquisition speed (shutter time) and focus depth. The welding head was set in flat position at the centreline of the plate and the trailing cold wire entered the weld pool with an angle of $40^{\circ}$ and a distance k of $2 \mathrm{~mm}$ (Fig. 3).

The sample plates had the dimensions $300 \mathrm{~mm} \times 100 \mathrm{~mm}$ $\times 10 \mathrm{~mm}$ and were made of the nickel base alloy 617 (UNS N06617). The chemical composition of the base plate is given in Table 1. The used welding flux complied with ISO 14174 - SA AB2. A similar solid wire electrode of the diameter $1.6 \mathrm{~mm}$ was used, as well as for the cold wire. Both had the same chemical composition (Table 1).

Three welding experiments were carried out with the welding parameters given in Table 2 . The first experiment was done by SAW without cold wire and served

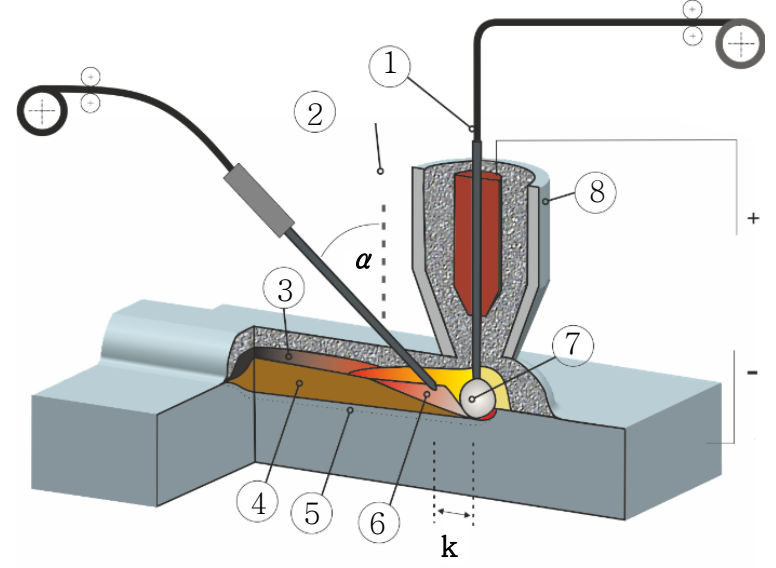

Fig. 3 Principle of SAW-CW, 1 - wire electrode, 2 - cold wire angle, 3 - solidified slag, 4 - solidified weld metal, 5 - base metal, 6 - weld pool, 7 - cavity, 8 flux hopper ${ }^{5}$ as reference, whereas the second and third experiment comprised SAW-CW with varying cold wire feed rate. During welding the ESPI device captured images (Fig. 4)over a time range of 120 seconds, so that cooling of the plate below $200{ }^{\circ} \mathrm{C}$ after welding could be achieved. The plates were removed from the clamping after cooling to room temperature (Fig. 5) and the residual stress was measured using incremental hole drilling (IHD)

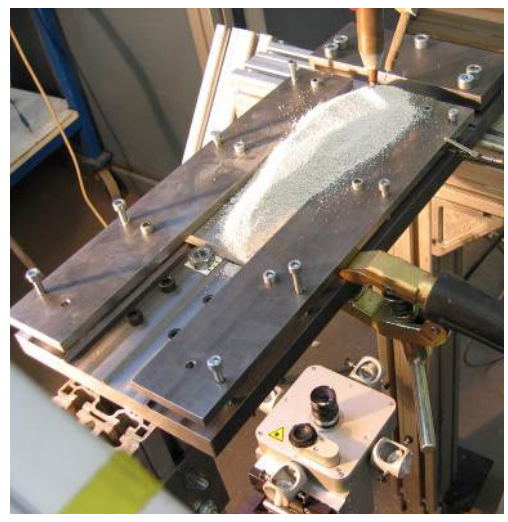

Fig. 4 ESPI strain measurement setup mounted under the SAW-CW welding head

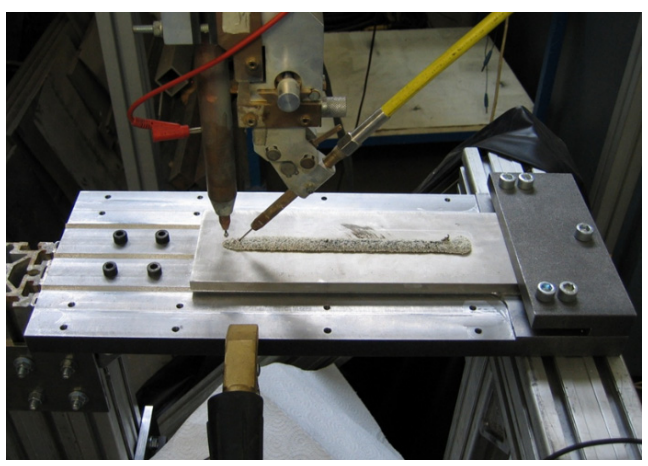

Fig. 5 Welded sample after removal of the clamps

Table 1 Chemical composition of base metal and welding wire (measured using spark optical emission spectrometry)

\begin{tabular}{|c|c|c|c|c|c|c|c|c|c|c|c|c|c|}
\hline & $\mathrm{C}$ & $\mathrm{Si}$ & $\mathrm{Mn}$ & $\mathrm{Cr}$ & $\mathrm{Mo}$ & $\mathrm{Fe}$ & $\mathrm{W}$ & $\mathrm{Al}$ & $\mathrm{Co}$ & $\mathrm{Nb}$ & $\mathrm{Ti}$ & $\mathrm{B}$ & $\mathrm{Ni}$ \\
\hline Base metal & 0,05 & 0,13 & 0,07 & 22,3 & 8,4 & 0,70 & 0,12 & 1,07 & 11,2 & 0,05 & 0,42 & 0,001 & bal. \\
\hline Wire electrode & 0,05 & 0,14 & 0,10 & 22,0 & 8,4 & 0,83 & 0,06 & 1,22 & 10,75 & 0,06 & 0,30 & 0,003 & bal. \\
\hline
\end{tabular}

Table 2 Welding parameters

\begin{tabular}{|c|c|c|c|c|c|c|c|c|}
\hline $\begin{array}{l}\text { Exp. } \\
\text { No. }\end{array}$ & $\begin{array}{c}\text { Welding } \\
\text { Voltage U } \\
\text { [V] }\end{array}$ & $\begin{array}{l}\text { Welding } \\
\text { Current I } \\
\text { [A] }\end{array}$ & $\begin{array}{c}\text { Electrode } \\
\text { Wire feed } \\
\text { speed }[\mathrm{m} / \mathrm{min}]\end{array}$ & $\begin{array}{l}\text { Cold Wire } \\
\text { feed speed } \\
{[\mathrm{m} / \mathrm{min}]}\end{array}$ & $\begin{array}{l}\text { Welding } \\
\text { speed } \\
{[\mathrm{cm} / \mathrm{min}]}\end{array}$ & $\begin{array}{l}\text { Heat Input } \mathrm{E} \\
{[\mathrm{kJ} / \mathrm{cm}]}\end{array}$ & $\begin{array}{c}\text { contact tip } \\
\text { distance }[\mathrm{mm}]\end{array}$ & $\begin{array}{c}\text { working } \\
\text { temperature }\end{array}$ \\
\hline 1 & 34,2 & 375 & \multirow{3}{*}{7,6} & 0 & 80 & 9,6 & \multirow{3}{*}{20} & \multirow{3}{*}{ RT } \\
\hline 2 & 34,6 & 366 & & 1,9 & 80 & 9,5 & & \\
\hline 3 & 34,8 & 360 & & 3,8 & 80 & 9,4 & & \\
\hline
\end{tabular}


Table 3 Evaluation of macrosections given in Fig. 7

\begin{tabular}{|c|c|c|c|c|c|}
\hline Exp. No. & Weld width & Penetration depth & Total weld cross sectional area & Penetration area & Dilution rate \\
\hline 1 & 13,4 & 5,1 & 67,8 & 40,7 & 0,6 \\
\hline 2 & 14,6 & 3,3 & 55,4 & 24,0 & 0,43 \\
\hline 3 & 14,8 & 3,5 & 72,4 & 26,1 & 0,36 \\
\hline
\end{tabular}

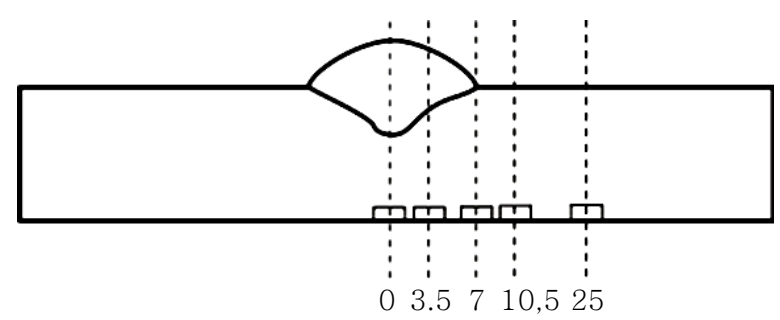

Fig. 6 Position of residual stress measurement by IHD on the backside of the welded plates

method with ESPI strain determination (Stresstech Prism) at the positions given in Fig. 6. This residual stress measurement technique implies a high speed drill milling cutter to drill a hole of small diameter (usually between 0.8 and $3.2 \mathrm{~mm}$ ) in distinct steps. Before the first drilling and after every depth increment, a speckle pattern from the sample surface around the hole is aquired by the ESPI system. This enables to measure the second order planar stress at the hole location. The hole unveils the residual stresses at the newly introduced surface through deformation. Within this investigation, a hole diameter of $1.6 \mathrm{~mm}$ has been used.

\section{Results}

The evaluation of the macrosections given in Fig. 7 shows that the penetration depth decreases when cold wire is fed into the weld pool. At the same time the total weld cross sectional area is lowest for $25 \%$ cold wire addition (relative to the main electrode feed speed), but increases when a higher cold wire addition ratio is used. Besides the measurement of electrical parameters, a good indicator for the separation between cold wire and arc cavity is the alloying element content of reactive elements such as Aluminum and Titanium. It can be seen that the cold wire addition leads to a remarkably increased aluminum content, but nearly no increase in titanium content was measured.

The in-situ strain measurement results (Fig. 8) are presented in Table 5. The measurement procedure was commenced after the electrode reached the position of the first measuring section (position a in Fig. 2). It can be seen that below the weld bead there is a compressive zone whereas besides the weld bead tensile strain is present. However the magnitude of transverse strain is much higher $25 \mathrm{~s}$ after the welding process has finished.

Table 4 Chemical composition of the weld metal (Sample $1-3$ ), measured by spark OES

\begin{tabular}{|c|c|c|c|c|c|c|c|c|c|c|c|c|c|}
\hline Exp. No. & $\mathrm{C}$ & $\mathrm{Si}$ & $\mathrm{Mn}$ & $\mathrm{Cr}$ & $\mathrm{Mo}$ & $\mathrm{Fe}$ & $\mathrm{W}$ & $\mathrm{Al}$ & $\mathrm{Co}$ & $\mathrm{Nb}$ & $\mathrm{Ti}$ & $\mathrm{B}$ & $\mathrm{Ni}$ \\
\hline 1 & 0,03 & 0,35 & 0,10 & 22,1 & 9,1 & 0,74 & 0,049 & 0,75 & 10,2 & 0,063 & 0,23 & 0,003 & bal. \\
\hline 2 & 0,04 & 0,30 & 0,10 & 22,4 & 9,1 & 0,75 & 0,046 & 0,90 & 10,2 & 0,063 & 0,25 & 0,004 & bal. \\
\hline 3 & 0,04 & 0,27 & 0,10 & 22,2 & 9,1 & 0,75 & 0,041 & 0,90 & 10,2 & 0,065 & 0,26 & 0,003 & bal. \\
\hline
\end{tabular}

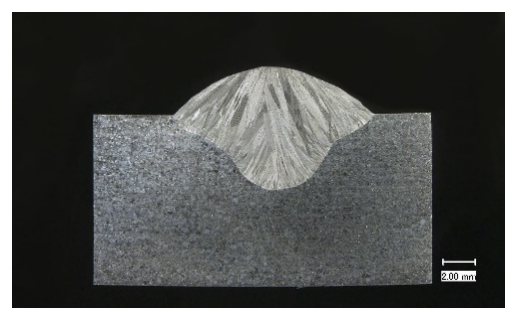

(a) $0 \%$ cold wire addition

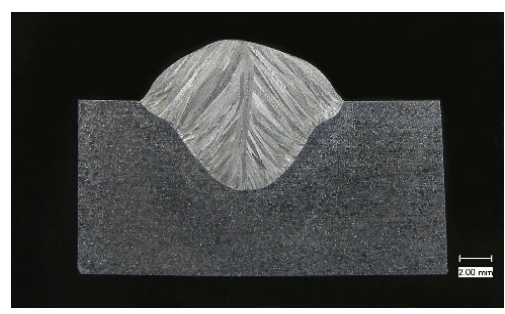

(b) $25 \%$ cold wire addition

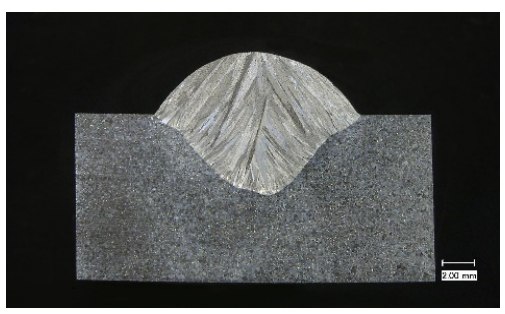

(c) $50 \%$ cold wire addition

Fig. 7 Macro cross-sections of the weld beads. Exp. No. 1(a) without cold wire addition (SAW), Exp. No. 2 (b) with 25 $\%$ cold wire addition (SAW-CW) and Exp. No. 3 (c) with $50 \%$ cold wire relative to the electrode speed 
Table 5 Strain profile transverse to welding direction measured on the backside of the sample through ESPI

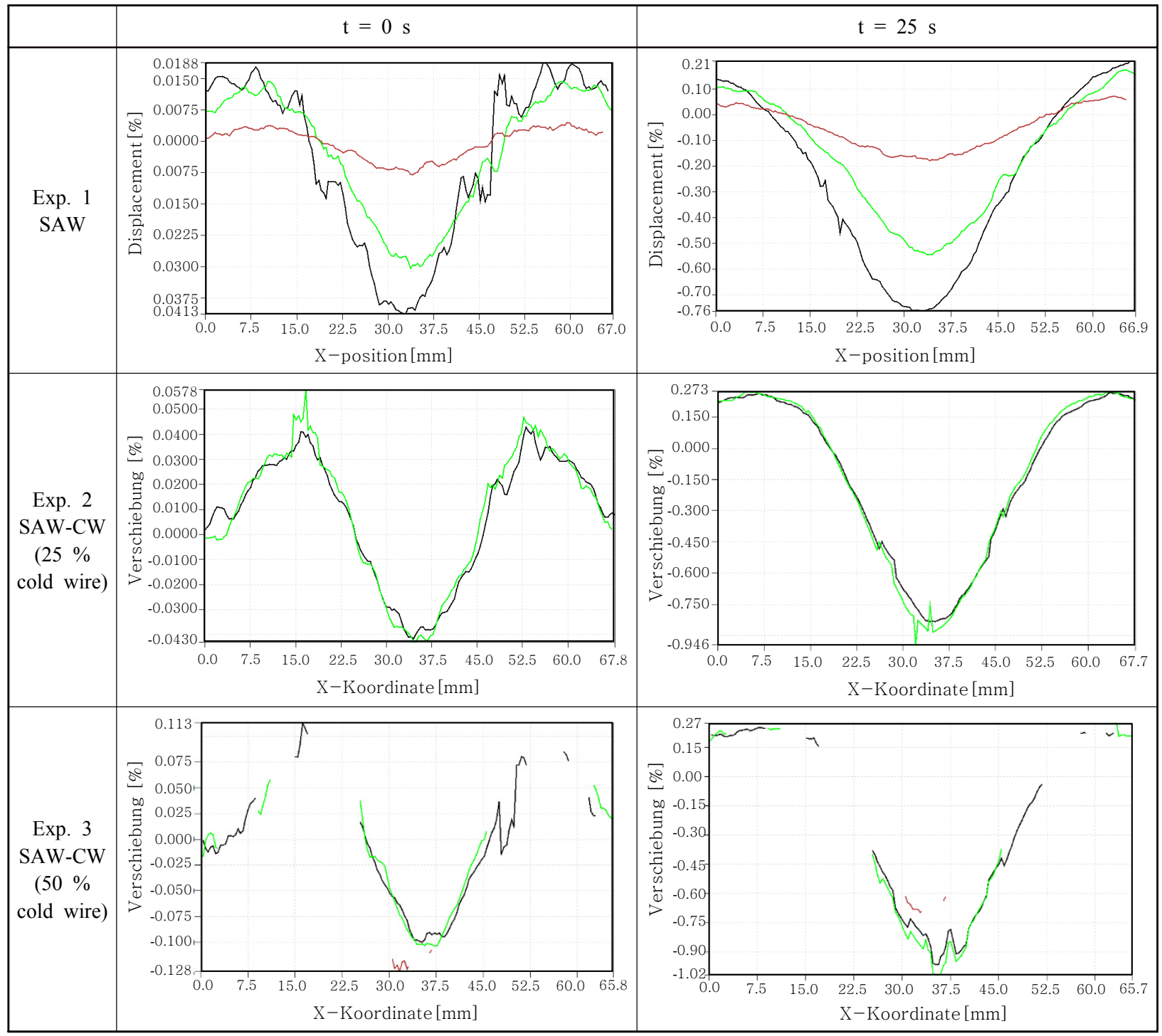

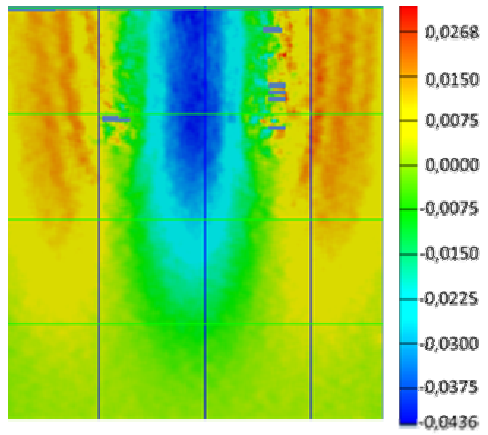

Fig. 8 Transverse strain map of SAW sample during welding

This is also the point in time where the maximum strain is reached. During the measurement of Exp. No. 1, the surface light diffusion coating $\left(\mathrm{MgCO}_{3}\right.$ suspension) lifted off the surface and lead to wrong results for the green and red strain profile, so that only the black pro- file was evaluated. In order to simplify the comparison of strain profiles, the local maximum values of the measurements were collected and merged into Fig. 9. For the first time step cold wire addition leads to narrower eccentric strain peaks. The magnitude of compressive strain is highest for the SAW-CW welds 2 and 3.

In Fig. 10 the transverse residual stress profiles on the backside of the plate in a depth of $0,05 \mathrm{~mm}$ are given. All measurements show tensile stress, except the measurement location $25 \mathrm{~mm}$ outside of the weld centreline, where compressive stress is found. The highest level of stress is found in Exp. No. 2, where 25 \% cold wire addition was used.

Cold wire addition leads to a change in weld bead geometry and weld metal chemistry. Since the cold wire influences the heat distribution, and through this, the fluid flow in the weld pool. For low cold wire addition the penetration depth increases (Table 3 ). If the cold 


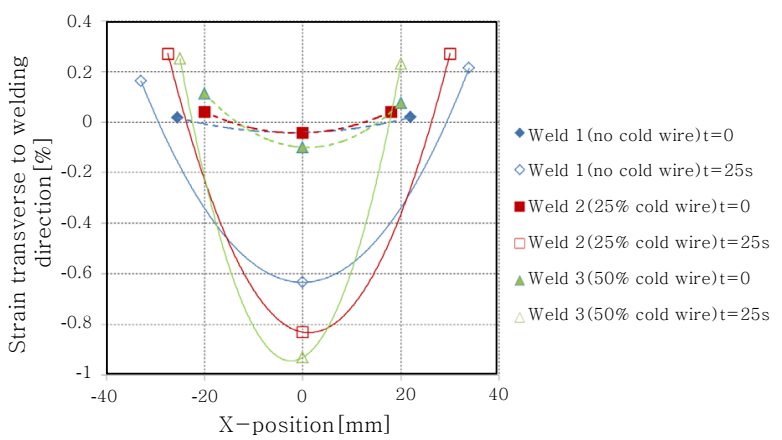

Fig. 9 Transverse strain comparison of three welded samples for different time steps $(\mathrm{t}=0$ : weld pool contact, $\mathrm{t}=25$ : maximum strain level during cooling), welding parameters acc. to Table 3

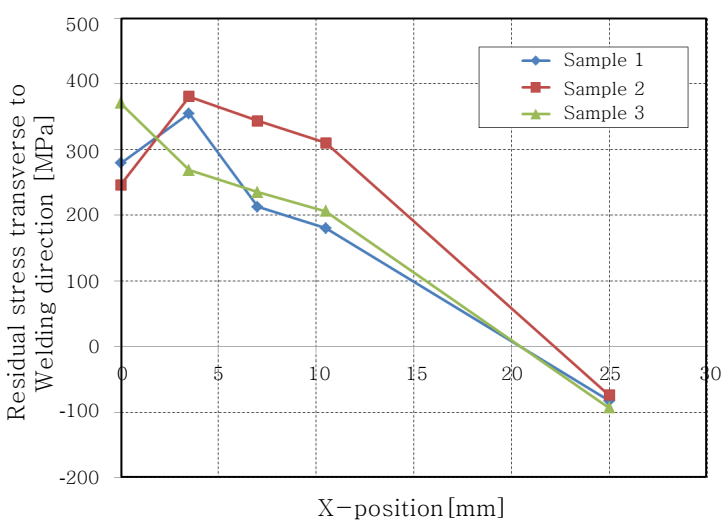

Fig. 10 Transverse stress measurement on the back side of the sample plate with $\mathrm{x}=0$ below the weld centerline

wire feed rate is increased, a lower penetration depth can be observed. This happens because the cold wire introduces a cold spot into the weld pool, leading to locally higher viscosity of the melt. A higher cold wire feed speed moves the cold spot under the electrode position, so that the penetration depth is reduced. The trailing cold wire enables to modify the weld metal chemistry, if the wire is fed into the weld pool without hitting the arc cavity. This is especially important to increase the content in reactive elements, such as Aluminum or Titanium. A possible resaon for the $\mathrm{Al}$ and $\mathrm{Ti}$ content not being influenced by an increased cold wire feeding could be that the used slag system prevents the weld pool from higher pickup amounts (Table 4). For the measured strain field during welding, it can be concluded that the compressive strain on the back side of the sample plate corresponds to weld shrinkage on the top side. Due to the restraint conditions, only small amounts of bending distortion of the plate were possible. Since the weld bead geometry depends on the cold wire addition, the narrower weld seam profile of cold wire added SA beads leaves a higher bending length between the weld seam and clamping, resulting in lower restraint, and therefore in higher compressive strain. Another influencing factor is the narrower thermal field, which was not examined in detail within this study, but can be concluded from other comparable experiments with cold wire addition ${ }^{8)}$. After cooling and release of the clamping force, the plate bends in a way that tensile stress apears on the backside of the sample plate. This behaviour can be explained when considering the stiffness of the heavily shrinked parts of the plate. The weld seam shrinked transverse to the welding direction due to solidification, which led to transverse tensile stress on the backside of the welded plates.

The presented results give an insight into basic thermomechanical reactions during SAW and CW-SAW of nickel base alloys. For the applied measuring methods, it came out that optical in-situ strain measurement using ESPI is feasible during SAW, but limited to laboratory welding setups, conditions and sample preparations. Nevertheless it adds the possibility to measure surface near strain during welding with high spatial resolution compared to neutron diffraction, whereas only point measurements in the sample depth are possible. In order to inprove the robustness of the strain measurement, digital image correlation will be applied in future work. Due to the larger optical features considered in this measurement method, it will be also possible to use a stereo-optical setup to measure distorted samples and out-of-plane-deformation. The artificial clamping will be substituted by common clamping devices and freeshrinking samples.

\section{Acknowledgements}

All presented investigations were conducted in the context of the Collaborative Research Centre

SFB1120 "Precision Melt Engineering" at RWTH Aachen University and funded by the German

Research Foundation (DFG). For the sponsorship and the support we wish to express our sincere gratitude.

\section{References}

1. Reisgen, U., Dilthey, U., Aretov, I., SAW Cold Wire Technology - Economic Alternative for Joining Hot Crack Sensitive Nickel-Base Alloys, Hot Cracking Phenomena in Welds II (2008), 215-237

2. Sharma, R., IIW-Doc. II-C-458-13, Investigation on the hot cracking sensitivity of nickel based alloys during cold wire submerged arc welding with externally loaded hot cracking tests, International Institute of Welding, (2013)

3. Sharma, R., Reisgen, U., Hofmann, M., Comparison of submerged arc welding process modification influence on thermal strain by in-situ neutron diffraction, Proceedings of ICRS10, Materials Research Proceedings 
2 (2016), 533-538. doi: 10.21741/9781945291173-90

4. L. Karlsson, H. Arcini, P Dyberg, S. Rigdal, M. Thuvander, Proceedings of. Stainless Steel World Conference Maastricht, $N L$, (2003), 283-294

5. Reisgen, U. Stein, L., DVS Fachbuchreihe Schweißtechnik, Band 13 : Fundamentals of joining technology. Welding, brazing and adhesive bonding, DVS Media, Düsseldorf, (2016)
6. Leendertz, J. A., Interferometric displacement measurement on scattering surfaces utilizing speckle effect. J. Phys. E: Sci. Instrum. 3(3) (1970), 214-218

7. Meguro, S., Muramatsu, Y., Application of ESPI System to Welding, Journal of Japan Welding Society, 24(3) (2006), 247-252 (in Japanese) 